\title{
ASSESSMENT OF MICROALBUMINURIA IN ESSENTIAL HYPERTENSIVES AND ITS RESPONSE TO ANGIOTENSIN-CONVERTING ENZYME INHIBITOR THERAPY
}

\author{
PREETI SHARMA ${ }^{1 *}$, PRADEEP KUMAR ${ }^{1}$, RACHNA SHARMA ${ }^{2}$, TRIPATHI GK $^{3}$, GAURAV GUPTA ${ }^{1}$
}

${ }^{1}$ Department of Biochemistry, Santosh Medical College \& Hospital, Ghaziabad, Uttar Pradesh, India. ${ }^{2}$ Department of Biochemistry, TSM Medical College and Hospital, Lucknow, Uttar Pradesh, India. ${ }^{3}$ Department of Medicine, Hind medical College and Hospital, Ghaziabad, Uttar Pradesh, India. Email: prcdri2003@yahoo.co.in

Received: 22 June 2016, Revised and Accepted: 25 August 2016

\section{ABSTRACT}

Objective: Objective is to study the prevalence of microalbuminuria among patients suffering from essential hypertension and also to evaluate the response of microalbuminuria to angiotensin-converting enzyme (ACE) inhibitors therapy.

Methods: The study conducted at Santosh Medical College and Hospital, Ghaziabad, on 300 patients with essential hypertension. After attaining baseline parameters in all patients, those newly diagnosed essential hypertensives with microalbuminuria not on any treatment were started on an ACE inhibitor (ramipril), for 8 weeks, after which all parameters were reassessed and comparison and statistical analysis were done to establish the prevalence of microalbuminuria and its response to therapy.

Results: In our study, mean microalbuminuria excretion was $101.79 \mathrm{mcg} / \mathrm{mg}$ creatinine at the beginning of the study and $80.20 \mathrm{mcg} / \mathrm{mg} \mathrm{creatinine}$ after 8 weeks of ACE inhibitor therapy, with $21.2 \%$ fall rate.

Conclusion: Microalbuminuria is an independent risk factor for the development or worsening of hypertensive nephropathy and endothelial dysfunction, thereby increasing the risk of micro- and macro-vascular complications.

Keywords: Microalbuminuria, Essential hypertension, Angiotensin-converting enzyme inhibitor therapy.

(C) 2016 The Authors. Published by Innovare Academic Sciences Pvt Ltd. This is an open access article under the CC BY license (http://creativecommons. org/licenses/by/4. 0/) DOI: http://dx.doi.org/10.22159/ajpcr.2016.v9s3.13618

\section{INTRODUCTION}

Microalbuminuria is very well-known marker of cardiovascular disorders [1] while its prognostic significance as marker is still controversial. The prevalence rate of microalbuminuria among hypertensives is reported from $4.7 \%$ to $46 \%$ [2]. According to national kidney foundation, microalbuminuria is defined as urine albumin excretion rate of approximately $30-300 \mathrm{mg} /$ day in at least three consecutive samples of nonketotic sterile urine [3]. It is now clearly demonstrated that microalbuminuria is a risk factor for the development of clinical proteinuria and decline of renal functions in hypertension [4] Based on pooling results from clinical trials, efficacy of different classes of antihypertensive agents suggests essentially equivalent blood pressure (BP)-lowering effect [5]. However, angiotensin-converting enzyme (ACE) inhibitors have a particularly useful role in treating patients with chronic kidney diseases because they diminish proteinuria and stabilize renal functions [6]. There is recent evidence that ACE inhibitors reduce the incidence of diabetes in patients with high cardiovascular risk [7] ACEs decrease intraglomerular pressure and proteinuria and may retard the rate of progression of renal insufficiency among both diabetics and nondiabetics [8]. There is evidence that a significant reduction in urinary albumin excretion (UAE) rate after 4-8 weeks of treatment with ACE inhibitors, in comparison to other treatment groups [5]. Hence, it becomes necessary to quantitatively study the renoprotective effect of ACE inhibitors among hypertensives. With this background, our objective is to study the prevalence of microalbuminuria among patients suffering from essential hypertension and also to evaluate the response of microalbuminuria to ACE inhibitors therapy.

\section{METHODS}

The study conducted at Santosh Medical College and Hospital, Ghaziabad, on patients who attended the medical outpatient department/inpatient department of Santosh Hospital. A total of 300 patients with essential hypertension were chosen for the study. The study was conducted in a time span of 1 year in 2014-15.

\section{Inclusion criteria}

Newly diagnosed hypertensives/not on any drug treatment having diastolic BP consistently over $90 \mathrm{mmHg}$ on two or more successive visits to the outpatient clinic and/or systolic BP over $140 \mathrm{~mm} \mathrm{Hg}$ on two or more successive visits to the outpatient clinic. Patients having UAE at the commencement of ACE inhibitor therapy between 30 and $300 \mathrm{mcg} / \mathrm{mg}$ creatinine and patients on no any hypertensive therapy in the past were included in the study.

\section{Exclusion criteria}

Patients suffering from secondary hypertension or having frank proteinuria or patients with clinical or laboratory evidence of hepatic, renal, thyroid, or any other major illness such as diabetes mellitus were not included in the study. Patients receiving nephrotoxic drugs (nonsteroidal anti-inflammatory drug, aminoglycosides), patients with deranged serum creatinine value or females on oral contraceptive pills were excluded from the study.

All patients were subjected to general medical and physical examination, fasting blood sugar, blood urea, serum creatinine, and creatinine clearance estimation. Haemoglobin, total leukocyte count, differential leukocyte count, erythrocytes sedimentation rate, serum $\mathrm{Na}^{+}$and $\mathrm{K}^{+}$, and Urine analysis including urine sugar, urine protein, microalbuminuria, urine microscopic examination for pus cells, red blood cells, casts, etc., were also investigated of all the participants.

After attaining baseline parameters in all patients, those newly diagnosed essential hypertensives with microalbuminuria not on any 
treatment were started on an ACE inhibitor (ramipril), beginning from $2.5 \mathrm{mg}$ OD to $10 \mathrm{mg}$ OD (dosage individualized to maintain target BP of $<140 \mathrm{mmHg}$ ) for 8 weeks, after which all parameters were reassessed, and comparison and statistical analysis were done to establish the prevalence of microalbuminuria and its response to therapy.

Following methods were used for measuring aforesaid parameters:

- Microalbumin - Immunoturbidimetric method [9]

- Urinary creatinine estimation - Jaffe's method [10]

- Fasting blood sugar - Glucose oxidase-peroxidase method [11]

- Urine sugar - Dipstick method [12]

- Blood urea - Glutamate dehydrogenase-urease method [13]

- $\mathrm{Na}^{+} / \mathrm{K}^{+}$- Ion selective electrode method with help of electrolyte analyzer [14]

\section{OBSERVATION AND RESULTS}

The study was conducted on 300 newly diagnosed patients of essential hypertension including 130 females and 170 males. Patients were in the age group of 41-60 years. 165 patients were having microalbuminuria $<30 \mathrm{mcg} / \mathrm{mg}$ creatinine, 83 patients had microalbumin $30-300 \mathrm{mcg} / \mathrm{mg}$ creatinine, $>300 \mathrm{mcg} / \mathrm{mg}$ creatinine level was observed in 52 patients.

Hence, the prevalence of microalbuminuria among essential hypertensives was found to be $27.7 \%$ in our study. Out of these, $43(30.8 \%)$ were males and remaining 40 (30.8\%) patients were females. These patients were given ramipril and reevaluated after 8 weeks (Table 1).

Our study showed a significant reduction in BP $(\mathrm{p}<0.001)$ and microalbuminuria $(\mathrm{p}<0.001)$ as a consequence of ACE inhibitor therapy (Table 2).

\section{DISCUSSION}

Microalbuminuria is one of the leading causes of mortality and morbidity all through the globe. In India, its prevalence lies between $17 \%$ and $21 \%$. The study was conducted to assess the prevalence of microalbuminuria among the patients suffering from essential hypertension and to study the role and renoprotective action of ACE inhibitors in reducing microalbuminuria over 8 weeks of therapy. In our finding, the prevalence of microalbuminuria was $27.7 \%$ out of $300 \%$. Palatini reported the prevalence of only 6\% in 2005 [15] while Sabharwal et al. in 2008 reported the $33.3 \%$ prevalence among 174 patients [16]. Pontremoli et al. reported $8 \%$ prevalence in their study [17]. Maharjan et al. in 2012 reported the prevalence of $17.7 \%$ [18]. The study done

Table 1: Frequency of microalbumin among essential hypertensive patients

\begin{tabular}{ll}
\hline Microalbumin (mcg/mg creatinine) & Frequency (\%) \\
\hline$<30$ & $165(55)$ \\
$30-300$ & $83(27.7)$ \\
$>300$ (up to frank proteinuria) & $52(17.3)$ \\
\hline
\end{tabular}

Table 2: Microalbumin and BP levels among microalbuminuric patients after ACE inhibitor therapy

\begin{tabular}{llll}
\hline Parameters & Mean \pm SD & $\begin{array}{l}\text { SD mean } \\
\text { error }\end{array}$ & p value \\
\hline SBP (0 weeks) & $162.18 \pm 18.11$ & 2.07 & $<0.001$ \\
SBP (8 weeks) & $136.89 \pm 10.46$ & 1.10 & \\
DBP (0 weeks) & $97.47 \pm 9.74$ & 1.11 & $<0.001$ \\
DBP (8 weeks) & $84.89 \pm 5.8$ & 0.66 & \\
Microalbumin (0 weeks) & $101.79 \pm 67.82$ & 7.78 & $<0.001$ \\
Microalbumin (8 weeks) & $80.20 \pm 54.47$ & 6.26 & \\
\hline
\end{tabular}

DBP: Diastolic blood pressure, SBP: Systolic blood pressure, SD: Standard deviation, ACE: Angiotensin-converting enzyme by Kim et al. in 2013 found the microalbuminuria prevalence of $14.1 \%$ among 40,473 patients in the Republic of Korea [19]. In our study, $25.3 \%$ of male hypertensive patients and $30.8 \%$ of female patients were albuminuric with maximum age group between 41 and 50 years. In the study done by Hunse et al., 10 out of 24 (41.7\%) patients in the age group 50-59 years had microalbuminuria [20]. In our study, mean microalbuminuria excretion was $101.79 \mathrm{mcg} / \mathrm{mg}$ creatinine at the beginning of the study and $80.20 \mathrm{mcg} / \mathrm{mg}$ creatinine after 8 weeks of ACE inhibitor therapy, with $21.2 \%$ fall rate. The study conducted by Jalal et al. in 2001, microalbumin level was $79.30 \mathrm{mcg} / \mathrm{mg}$ creatinine at the beginning and $73.96 \mathrm{mcg} / \mathrm{mg}$ creatinine after 8 weeks showing a fall of $6.7 \%$ [21]. Abate et al. in 1995 noted the disappearance of microalbuminuria in $65 \%$ patients, reduction in $17.5 \%$, and no change in $17.5 \%$ with a 6 months follow-up period [22].

Thus, results from our study are in conjunction with those from other studies, using similar or different drugs and prolonged treatment duration.

\section{CONCLUSION}

From the outcome of our and several other studies, it can be concluded that microalbuminuria is an independent risk factor for the development or worsening of hypertensive nephropathy and endothelial dysfunction, thereby increasing the risk of micro- and macro-vascular complications. Drug acting on renin-angiotensin-aldosterone helps in reduction of UAE apart from their BP-lowering action.

\section{REFERENCES}

1. Jensen JS, Feldt-Rasmussen B, Strandgaard S, Schroll M, BorchJohnsen K. Arterial hypertension, microalbuminuria, and risk of ischemic heart disease. Hypertension 2000;35(4):898-903.

2. Park K. Hypertension. Text Book of Preventive and Social Medicine. $22^{\text {nd }}$ ed. Jabalpur: Banarasi Das Bhanot; 2014.

3. Kannel WB, Stampfer MJ, Castelli WP, Verter J. Prognostic significance of proteinuria. Framingham heart study. Am Heart J 1984;108(5):1347-52.

4. Hillege HL, Fidler V, Diercks GF, van Gilst WH, de Zeeuw D, van Veldhuisen DJ, et al. Urinary albumin excretion predicts cardiovascular and noncardiovascular mortality in general population. Circulation 2002;106(14):1777-82.

5. Redon J. Renal protection by antihypertensive drugs: Insights from microalbuminuria studies. J Hypertens 1998;16:2091-100.

6. Maki DD, Ma JZ, Louis TA, Kasiske BL. Long-term effects of antihypertensive agents on proteinuria and renal function. Arch Intern Med 1995;155(10):1073-80.

7. Parving HH. Microalbuminuria in essential hypertension and diabetes mellitus. J Hypertens Suppl 1996;14(2):S89-93.

8. Parving HH. Benefits and cost of antihypertensive treatment in incipient and overt diabetic nephropathy. J Hypertens Suppl 1998;16(1):S99-101.

9. Massoubre C, Orsonneau JL, Massoubre B, Blanchardie P, Lustenberger P. Microalbuminuria: Evaluation of an immunoturbidimetric method and an immunonephelemetric method. Ann Biol Clin (Paris) 1989;47(7):391-5.

10. Available from: http://www.clinchem.org/content/14/3/222.full.pdf.

11. Estimation of Blood Glucose by Glucose Oxidase Method; 2012. Available from: http://www.vlab.amrita.edu. [Last retrieved on 2016 Jun 20].

12. Available from: http://www.healthline.com/health/glucose-test-urine

13. Available from: http://www.aveconhealthcare.com.

14. Burtis CA, Bruns DE. Tietz Fundamentals of Clinical Chemistry and Molecular Diagnostics. Ch. 24. St. Louis: Elsevier Saunders; 2015. p. 410-7.

15. Palatini P. Microalbuminuria in hypertension. Curr Hypertens Rep 2003;5(3):208-14.

16. Sabharwal RK, Singh P, Arora MM, Somani BL, Ambade V. Incidence of microalbuminuria in hypertensive patients. Indian J Clin Biochem 2008;23(1):71-5.

17. Pontremoli R, Leoncini G, Ravera M, Viazzi F, Vettoretti S, Ratto E, et al. Microalbuminuria, cardiovascular, and renal risk in primary hypertension. J Am Soc Nephrol 2002;13 Suppl 3:S169-72.

18. Maharjan BR, Bhandary S, Sunuwar L, Shrestha A, Ranjitkar N. Association of hypertension with microalbuminuria and lipid profile in 
the local population of Patan. Nepal Med Coll J 2012;14(2):157-62.

19. Kim YS, Kim HS, Oh HY, Lee MK, Kim CH, Kim YS, et al. Prevalence of microalbuminuria and associated risk factors among adult Korean hypertensive patients in a primary care setting. Hypertens Res 2013;36(9):807-23

20. Study of Microalbuminuria in Patients of Essential Hypertension Hunse; 2011. Available from: http://www.14.139.159.4:8080/jspui/ bitstream/123456789/5501/1/Pragna\%20Hunse.PDF.
21. Jalal S, Sofi FA, Alai MS, Siddiqqi MA, Bhat MA, Khan KA, et al. Prevalence of microalbuminuria in essential hypertension: A study of patients with mild to moderate hypertension. Indian J Nephrol 2001;11:6-11

22. Abate D, Cafà R, Castellino AR, Maligno C, Sorrusca F, Abate FC. Variations in microalbuminuria in essential hypertension treated with ACE inhibitors, calcium antagonists and their association. Minerva Cardioangiol 1995;43(7-8):303-7. 